ISSN 2693-2490

\title{
Effect of Quick Coherence Technique on Psychophysiological Coherence, Heart Rate, Stress, Anxiety, Depression and Feeling State in Young Adults in India
}

Journal of Psychology and Neuroscience

Research Article

Shilpa Jasubhai

Consultant Clinical Psychologist, Ahmedabad, Gujarat, India.

\author{
*Correspondence author \\ Dr. Shilpa Jasubhai \\ Consultant Clinical Psychologist \\ Ahmedabad \\ Gujarat \\ India
}

Submitted : 26 Feb 2021 ; Published : 11 Mar 2021

\begin{abstract}
HeartMath technology is an innovative technique to improving emotional mental health. A small-scale study was conducted to investigate the effect of quick coherence technique on psychophysiological coherence, stress, anxiety, depression and feeling state in young adults in India. Present study is in line with the past research done by S.D. Edwards (2016) on 'Influence of Heartmath Quick Coherence Technique on Psychophysiological Coherence and Feeling States'. Six postgraduate students who complained of stress, anxiety and depression were included in the present study. There were 4 female and 2 males between the age group of 22-28 years. They were screened for stress, anxiety and depression using DAS 21 scale and their physiological coherence score was recorded using emWave system. They were asked to rate their feeling states (anger, sadness, happiness and calmness) before and after each session. Six (twice a week) sessions were conducted using quick coherence technique. In the initial session they were taught quick coherence technique. They were given heart focused breathing exercise and affirmation as a home plan. After six sessions their physiological coherence score was recorded using emWave system. Then they were screened for stress, anxiety and depression using DAS 21 scale. There was a significant improvement in psychophysiological coherence, anxiety, stress and feeling state after quick coherence training. The present study supports the past research done by S.D. Edwards (2016) where the results showed significant changes in psychophysiological coherence, negative feeling states and positive feeling state after five sessions.
\end{abstract}

Keywords: Quick Coherence Technique, Stress, Depression, Anxiety, Psychophysiological coherence, Heart rate, Feeling state

Introduction

The year 2020 has been a challenging year for everyone. Corona virus pandemic has created a lot of insecurities and uncertainties in people worldwide. Stress, anxiety and frustration have become a part of our everyday life. A survey done by ILO (International Labour Organization, August 2020) reported that $50 \%$ youth population got affected mentally due to COVID lockdown and 1 in 2 youngsters were prone to experiencing symptoms of anxiety and depression. Working from home, extended working hours, lack of socializing, and additional responsibilities at home made many experience the symptoms of burnout, stress, anxiety and depression [43].

Keeping in mind the above information the researcher decided to conduct a small study. Present study is in line with the past research done by S.D. Edwards (2016) on 'Influence of Heartmath Quick Coherence Technique on Psychophysiological Coherence and Feeling States'. The results revealed clinically significant improvement in psychophysiological coherence and feeling state after five sessions of quick coherence technique [39].

The Quick Coherence technique of the HeartMath system selected for the present study basically involves heart focused breathing and feeling. HeartMath system (emWave Pro) uses self-regulation techniques to relieve stress, improve resilience, overall health and alter negative angry, anxious, bored and sad feelings into excited, happy, peaceful or contented feelings respectively [12]. A scientific research done by McCraty \& Shaffer (2015) indicated that neural signals from the heart affect the brain centres which are involved in emotional selfregulation [33]. Various studies have indicated that HeartMath techniques improve positive emotional states [28,29,30]. Studies conducted by HeartMath institute reported that heart rate variability, or heart rhythms were reflective indicators of one's emotional states and different patterns of heart activity have specific effects on cognitive and emotional function [20]. 
Constant stress plays a major role on physical and emotional health and cognitive functions [45]. Won E, Yong-Ku K. (2016) reported that there is a linkage between stress and depression or mood disorders and their effect on the autonomic nervous system (ANS), hormones and the immune system [47]. ANS consists of sympathetic nervous system (SNS) which controls fight-or-flight response and Parasympathetic nervous system (PNS) which restores the energy and body balance after the trigger is gone. For physical and emotional well-being, it is important to maintain the balance between SNS and PSN. Stress impairs this balance by over activating the SNS [44].

HRV is a key indicator of the sympathetic and the parasympathetic nervous system activity [13]. Higher level of HRV is associated with emotional resilience and stress vulnerability [5].

\section{Literature Review}

S.D. Edwards (2016) investigated the influence of HeartMath quick coherence technique on psychophysiological coherence and feeling states and reported a significant change in percentages of high psychophysiological coherence, decreased feelings of sadness and increased feelings of peacefulness [39]. Karavidas et al. (2007) \& Siepmann M et al (2008) in a study reported that biofeedback techniques, which uses rhythmic breathing to increased HRV and helped reduce depression $[24,40]$. Jerath R. et al (2015) in a study on self-regulation of breathing as a primary treatment for anxiety concluded that breathing techniques could be used as an initial treatment for stress, anxiety, depression, and some emotional disorders [21]. Lucy H. Field et al (2018) in a study on influence of HeartMath training program on physiological and psychological variables received positive results with heartmath training [27]. Jorina Elbers \& Rollin McCraty (2020) in a study on HeartMath approach to self-regulation and psychosocial well-being concluded that change in the heart rhythm plays an important role in enabling higher cognitive functions, creating emotional flexibility, and helping social connectedness [22].

Results of a study conducted by R McCraty et al (1995) suggest that positive emotions lead to alterations in HRV [28]. Chambers and Allen (2002) found that increased HRV was strongly related to a decrease in severity of depression in women receiving acupuncture for major depression [11]. Appelhans B. \& Luecken L. (2006) in a study on heart rate variability as an Index of regulated emotional response, reported that heart rate variability (HRV) analysis is an objective measure of regulated emotional responding and can increase the understanding of emotion in social and psychopathological processes [5]. A study conducted by Bradley R.T. et at (2010) showed positive association between reduced test anxiety and increased psychophysiological coherence and improved test performance [8]. Hartmann Ralf et al (2019) conducted a study on heart rate variability as an indicator of clinical state in depression and concluded that change in HRV parameter values correlated with changes in the severity of depressive symptoms [17].

However, there was not enough data available on the effect of quick coherence technique on psychophysiological coherence, stress, anxiety, depression and feeling state in young adults in India. Further research is needed to understand the longterm effect of the quick coherence technique on HRV, psychophysiological coherence, stress, depression, anxiety and feeling state in the Indian context.

\section{Present Study}

The main objective of the present study was to study the efficacy of quick coherence technique on psychophysiological coherence, stress, anxiety, depression and feeling state in Indian young adults.

The participants who complained experiencing symptoms of stress, anxiety and depression were randomly selected and were asked to sign the consent form and give demographic details. They were assessed for stress, anxiety and depression using DAS 21 and their psychophysiological coherence and HRV scores were recorded using the emWave system pre- and postsessions. They were given 6 (twice a week) training sessions on quick coherence technique using the emWave system. They were asked to rate the feeling states (anger, sadness, happiness and calmness) on a 10-point rating scale before and after each session. According to HeartMath research different patterns of heart activity have discrete effects on emotional and cognitive function. The heart rhythm pattern is erratic during stress and anxiety and affects the brain's emotional processes [12].

Findings from the study done by S.D. Edwards (2016) led to the assumption of the research hypothesis that HeartMath quick coherence technique training of at least six sessions would be associated with higher psychophysiological coherence levels, decreased stress, anxiety, depression, negative feeling state and increased positive feeling state.

Stress

The dictionary meaning of stress is "a state of mental or emotional strain or tension resulting from adverse or demanding circumstances." [36] In psychology, stress is a feeling of strain, pressure or a type of psychological pain [42].

Baum,A. (1990) defined stress as any uncomfortable "emotional experience accompanied by predictable biochemical, physiological and behavioural changes." [6] Research by Baum, A. \& Polsusnzy, D. (1999), shows that stress can contribute to the development of serious health issues, such as heart disease, depression, obesity, anxiety, insomnia, muscle pain, high blood pressure and a weakened immune system [7]. External stress or internal perceptions can cause an individual to experience anxiety or other negative emotions surrounding a situation, which they believe to be stressful [14].

\section{Anxiety}

The dictionary meaning of anxiety is "a feeling of worry, nervousness, or unease about something with an uncertain outcome." [34] According to the American Psychological Association (APA) "Anxiety is an emotion characterized by feelings of tension, worried thoughts and physical changes 
like increased blood pressure. People with anxiety disorders usually have recurring intrusive thoughts or concerns. They may avoid certain situations out of worry. They may also have physical symptoms such as sweating, trembling, dizziness or a rapid heartbeat [1].

The essential features of generalized anxiety disorder according to DSM V are "excessive anxiety and worry about a variety of topics, events, or activities. Worry occurs more often than not for at least 6 months and is clearly excessive. Excessive worry means worrying even when there is nothing wrong or in a manner that is disproportionate to the actual risk" [3].

\section{Depression}

Dictionary meaning of depression is "feelings of severe despondency and dejection [35]". According to APA "Depression is more than just sadness. People with depression may experience a lack of interest and pleasure in daily activities, significant weight loss or gain, insomnia or excessive sleeping, lack of energy, inability to concentrate, feelings of worthlessness or excessive guilt and recurrent thoughts of death or suicide [2]."

According to DSM V Depression symptoms can vary from mild to severe and a person may experience feeling of sadness, loss of interest, changes in appetite, change in sleep, loss of energy, feeling of worthlessness, suicidal thoughts, difficulty concentrating and the symptoms should last at least for two weeks [3].

\section{Psychophysiological Coherence}

Heart rate variability (HRV)

Heart rate variability (HRV) is a measure of the beat-to-beat changes in heart rate. Our breathing patterns, physical exercise, and thoughts influence HRV. HRV helps to understand the interactions between physiological, mental, emotional and behavioural processes. According to HRV analysis the heart is a sensitive marker for emotional changes, which is reflected in heart rhythm patterns. It reflects a person's capacity to adapt effectively to stress and environmental demands and is an important indicator of both physiological resilience and behavioural flexibility [12].

\section{HRV Patterns (Heart Rhythms)}

According to the HeartMath, heart rhythm patterns reflect the inner balance and emotional state of the mind. Our feelings and emotions directly affect our heart rhythm pattern. Varying heart rate is plotted over time and the overall plot of the waveform is called the heart rhythm pattern. Different patterns of heart activity have different effects on cognitive and emotional function of the brain. During stress, anxiety and negative emotions, the heart rhythm pattern is irregular and erratic. HeartMath Scientists call this an incoherent heart rhythm pattern. This restricts the ability to think clearly, remember, learn and affect our emotions. When positive emotions are experienced the heart rhythm pattern becomes smooth and harmonious which is called coherent heart rhythm pattern.

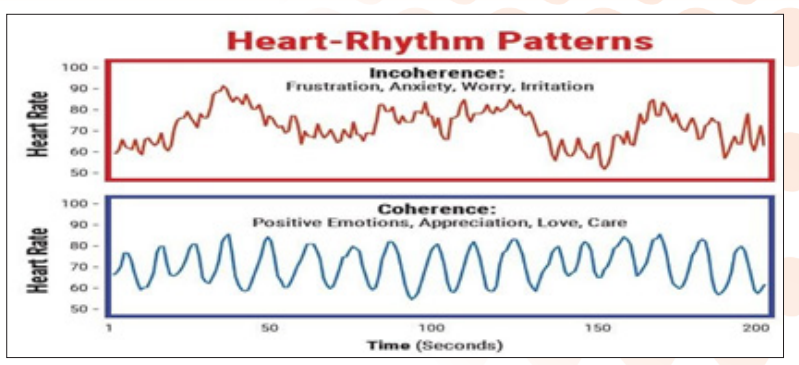

According to Rollin McCart, Coherence is an optimal physiological state when the heart, mind and emotions are in alignment and this prevents and reduces stress, increases resilience and improves emotional wellbeing. This is called psychophysiological coherence because there is an increased harmony in both the psychological and physiological processes $[12,17,18,26,32]$.

\section{Feeling State}

An emotion is a state of feeling such as happiness, love, fear, anger. In psychology, emotion is often defined as "a complex state of feeling that results in physical and psychological changes that influence thought and behaviour." According to the American Psychological Association (APA), a complex reaction pattern, involving experiential, behavioural and physiological elements, by which an individual attempts to deal with a personally significant matter or event $[23,38]$."

Some of the emotions we experience uplift us while others drain us. Every time you make an emotional shift, like from joy to sadness, anger to calm, peacefulness to anxiety etc., a lot of biochemical changes take place inside the body. Uplifting emotions increase our resilience while stress creates chaos in the nervous system and drains our energy [12].

We can gain better control over our emotions once we become aware of them. Participants were asked to rate their feelings of anger, sadness, happiness and calmness before and after each training session.

\section{Hypothesis}

HO - There is no significant effect of quick coherence technique on psychophysiological

coherence, stress, anxiety, depression and feeling state post intervention in young adults in India.

H1 - There is a significant effect of quick coherence technique on psychophysiological coherence, stress, anxiety, depression and feeling state post intervention in young adults in India.

\section{Material}

- $\quad$ Depression, Anxiety and Stress Scale 21 (DASS 21)

- Emwave System

- Feeling state form

- Consent Form

- Demographic Information Form 


\section{Method}

Participants

Six participants ( 2 male and 4 female) in the age group of 22 to 28 years were randomly selected from Ahmedabad, India and were screened for psychophysiological coherence using emWave Pro system [12], stress, anxiety, depression using Depression, Anxiety, Stress Scales 21 (DASS-21)[25] and feeling state.

Doc Childre (1991) is the founder of the HeartMath Institute and the emWave system. It is based on years of scientific research on the psychophysiology of stress, emotions, and the interactions between the heart and the brain. The emWavePro consists of PC based software, a USB sensory unit is attached to the computer. The ear sensor is clipped to the earlobe which detects the pulse easily. The software accurately measures and records HRV, provides values of physiological coherence and displays the feedback on the screen. The HeartMath system uses self-regulation techniques to relieve stress, improve resilience and health [12,39].

The DASS 21 scale (Lovibond, S.H. \& Lovibond, P.F., 1995) is a set of three self-report scales designed to measure the negative emotional states of depression, anxiety and stress. Participants were asked to specify on a 4-point scale the extent to which they had experienced negative emotional states of depression, anxiety, and stress during the past week. Each of the three DASS-21 scales contains 7 items, divided into subscales with similar content. The development of DASS-21 was based on the assumption that the difference between the stress, anxiety and depression experienced by normal subjects and clinical patients is mainly of degree [25].

The participants were informed about the past research on heart rhythm quick coherence technique training and its physiological and psychological benefits. They were asked to sign the consent form and provide demographic information. Their psychophysiological coherence score was recorded and were screened for stress, anxiety and depression using DASS 21 pre- and post- 6 sessions of training.

The participants were given 6 (twice a week) individual training sessions using quick coherence technique. Participants were asked to rate their feeling state at the beginning of each session and after each session on the scale of 1 to 10 . The feeling states are: anger, sadness, happiness and calmness. Quick coherence technique was taught. In each session Quick coherence technique training was given using Heartmath's coherence coach. The results were analysed using small sample ' $t$ ' test.

\section{Procedure}

Six, (twice a week) individual training sessions were conducted using quick coherence technique.

\section{Quick Coherence Technique}

The Quick Coherence technique is a simple technique that uses the power of the heart and breathing to balance thoughts and emotions. Quick coherence puts your heart in a more coherent mode and has a carryover effect so you feel more connected and centered.

Benefits of controlled breathing originated from the science of Yoga. Effect of breathing on mind and body and reducing anxiety, depression and stress is well known. When a person is in stress, stress hormones are secreted and it may cause speedy breathing, increased pulse or blood pressure. Deep breathing activates the parasympathetic nervous system, which reverses the stress response in the body by slowing down heart rate, lowering blood pressure, and calming the body and mind.

Breathing was an important aspect of the study because it was the first step of the technique participants used to self-regulate their feeling states. Slow breathing at about 5-7 breath cycles per minute helps control the heart's rhythmic activity, enable identification and focus on a particular positive emotion. The chosen Quick Coherence technique for the present study basically involves heart focused rhythmic breathing and reexperiencing positive emotions which helps reduce negative feelings like anger and sadness and helps increase positive feelings like happiness and calmness. Past research has shown that positive emotions are linked with psychophysiological coherence and reexperiencing the positive emotional memory have a stronger effect on physical, mental and emotional wellbeing.

The procedure involved participants to focus on the screen and inhale as the ball goes up and exhale as the ball comes down i.e., inhaling for 5 seconds and exhaling for 5 seconds. Then they were asked to focus their attention in the area of the heart and imagine that the breath is flowing in and out of their heart, breathing a little slower and deeper than usual, inhaling for 5 seconds and exhaling for 5 seconds.

Once they were able to focus on the heart, they were asked to make a sincere attempt to recreate a feeling such as care for someone or recalling a beautiful memory and trying to re-experience the same feelings again or simply focusing on a feeling of calm or ease as they continued breathing. This training was given for 10 minutes in each session. They were given a home plan of a heart focused breathing exercise with inhaling for 5 seconds and exhaling for 5 seconds for about 4 to 5 minutes, affirmation and cognitive restructurin $[10,12,19,32,37]$.

\section{Statistical Methods}

The statistical analysis was done using small samples $t$ test. A statistical significance in t test indicates whether the difference between the averages of two groups most likely reflects a "real" difference in the population from which the groups were sampled. The researcher was interested in finding out whether there was an improvement in stress, anxiety, depression, psychophysiological coherence and feeling state post intervention $[15,41]$. 
Results

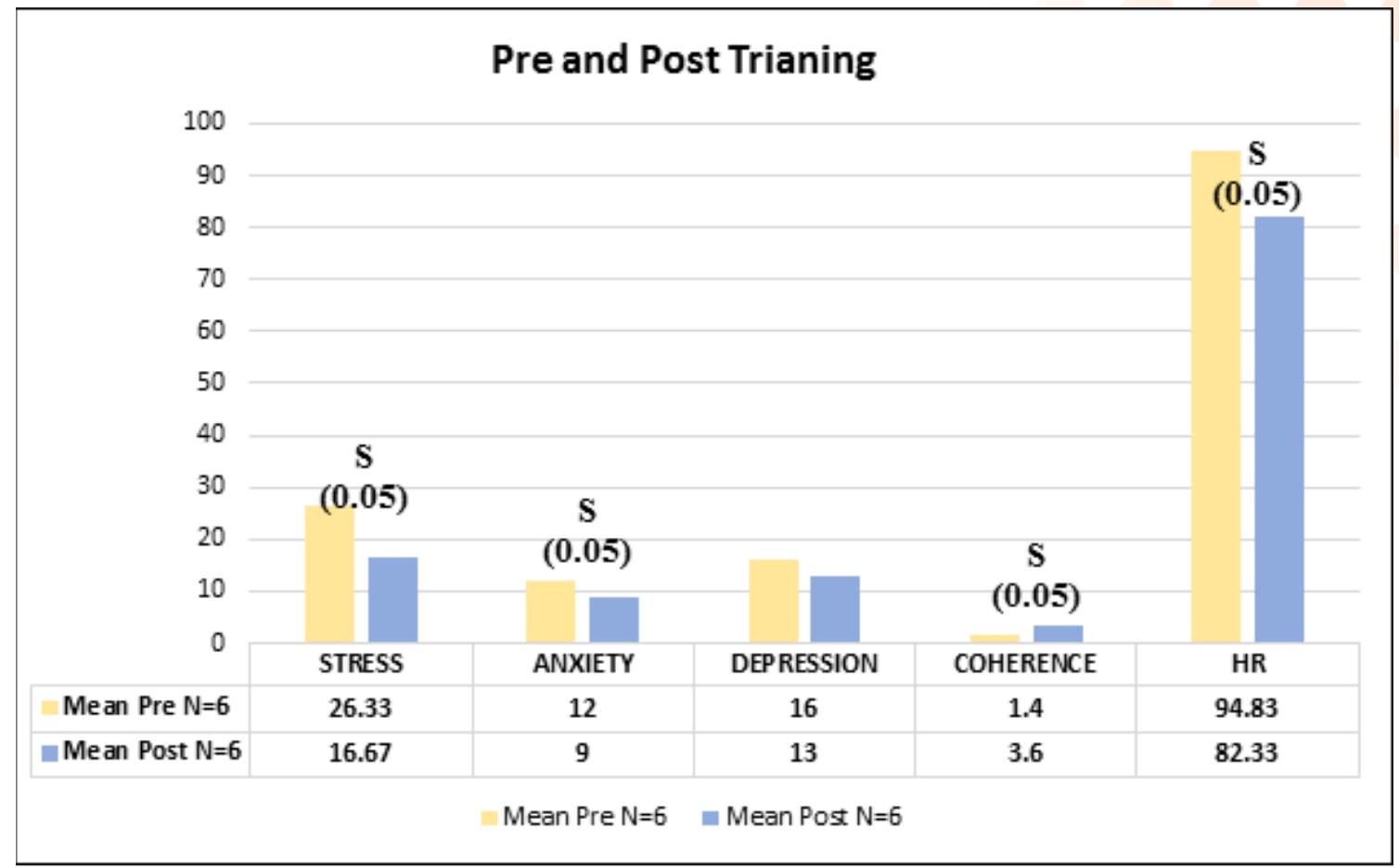

Graph 1: Pre and Post Training

The total sample size was 6 , consisting of 4 women and 2 men between the age group of $22-28$ years. Average pre-test scores on stress, anxiety, depression, coherence and heart rate were $26.33,12,16,1.4$ and 94.88 respectively. Pre intervention average score on stress was in severe range and scores on depression and anxiety were in moderate range. Average coherence score was very low and heart rate was high. Post intervention there was a significant improvement in stress, anxiety, coherence and heart rate. Post training sessions, the average stress, anxiety and depression scores were 16.67, 9 and 13 respectively. Stress, anxiety and depression came down to a mild range. The average coherence score increased to 3.6 and average heart rate came down to 82.33 .

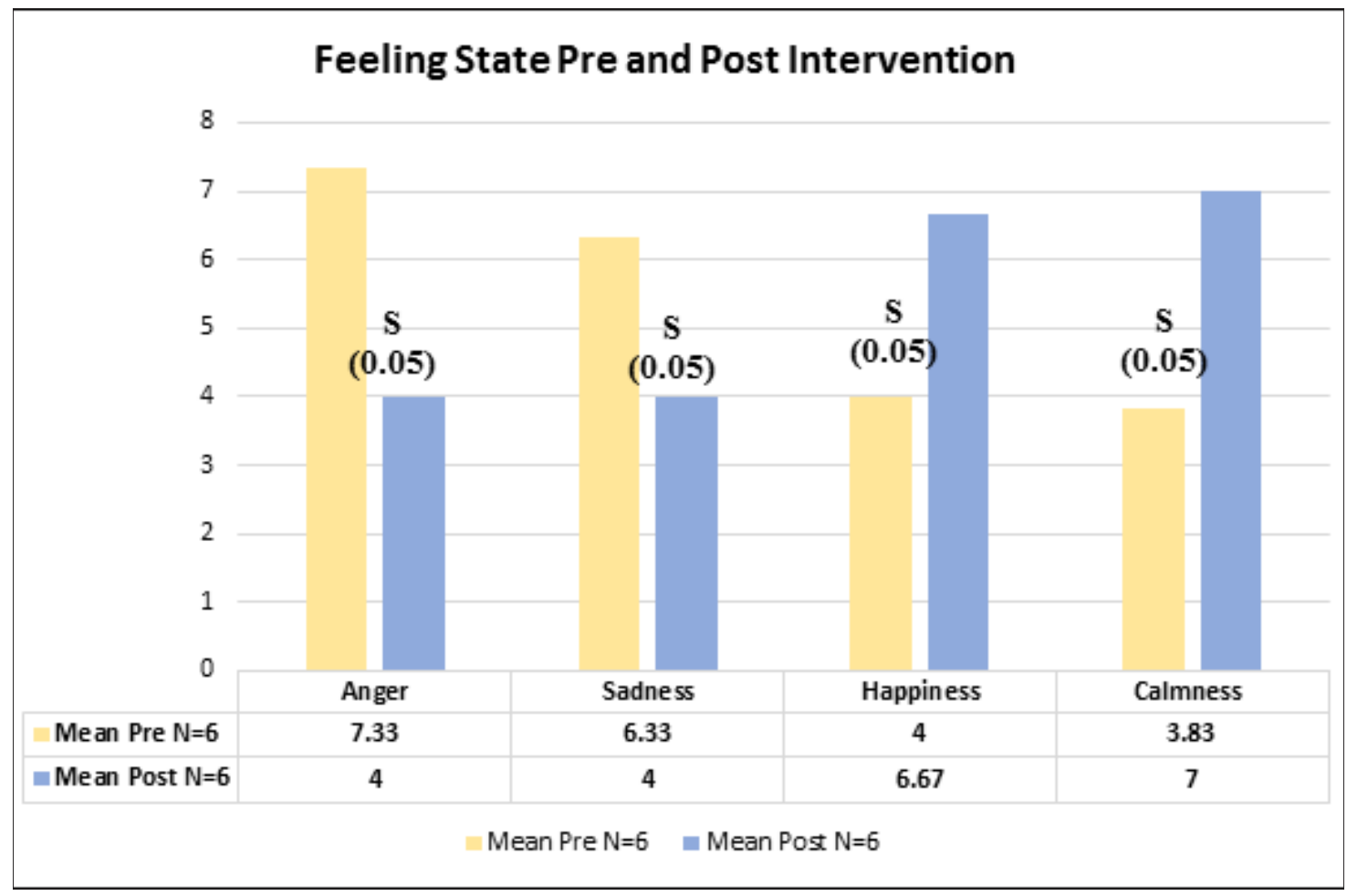

Graph 2: Feeling State Pre and Post Intervention 
Average pre-test scores on feeling state of anger, sadness, happiness and calmness were $7.33,6.33,4$ and 3.83 respectively. After 6 sessions of quick coherence training there was a significant improvement in feeling state of anger, sadness, happiness and calmness. The average score of feeling state of anger and sadness came down to 4 and average score on feeling state of happiness and calmness improved to 6.67 and 7 respectively.

\section{Discussions}

After 6 sessions of quick coherence training there was a significant improvement in stress, anxiety, psychophysiological coherence and heart rate. Post intervention average scores on stress, anxiety and depression came in mild range; psychophysiological coherence increased and heart rate came down.

Findings are highly consistent with prior studies that confirmed that HRV parameter values correlated with changes in the severity of stress, anxiety and depressive symptoms such as Ginsberg J. et al (2010), Jorina Elbers \& Rollin McCraty (2020), Hartmann Ralf et al (2019) and McCraty R., Atkinson M., Tomasino (2009) [16,17,22,30].

After 6 sessions of quick coherence training, there was a significant improvement in feeling state. Results are highly consistent with prior studies that confirmed that positive emotions lead to alterations in HRV such as Appelhans B. \& Luecken L. (2006), R McCraty et al (1995), S. D. Edward (2016) and Trivedi Gunjan Y \& Saboo Banshi (2019). Results support a case study conducted by Wellness Space (2018) where they concluded that 10 minutes chanting increased coherence and helped reinforce positive emotions $[5,28,39,45]$.

According to the article published by Dr. Sheila Patel (2020) on "Breathing for Life: The Mind-Body Healing Benefits of Pranayama", deep breathing activates the parasympathetic nervous system, which reverses the stress response in the body by slowing down heart rate, lowering blood pressure, and calming the body and mind. (37) Past Researchers have documented that a regular practice of deep breathing can have various benefits which include reduced anxiety and depression, lower blood pressure, increased energy levels, improved immunity, decreased feelings of stress etc. The results of the present study support the previous findings and conclude that deep breathing and focusing of the positive memory can help reduce stress, anxiety and depression, improve feeling state, psychophysiological coherence and heart rate.

One of the subjects who was 25-year-old female, had severe stress, moderate anxiety and depression and her coherence was 1.2 and heart rate was 123 pre intervention. Her score on anger was 7 , sadness was 8 , happiness was 3 and calmness was 3 pre intervention.

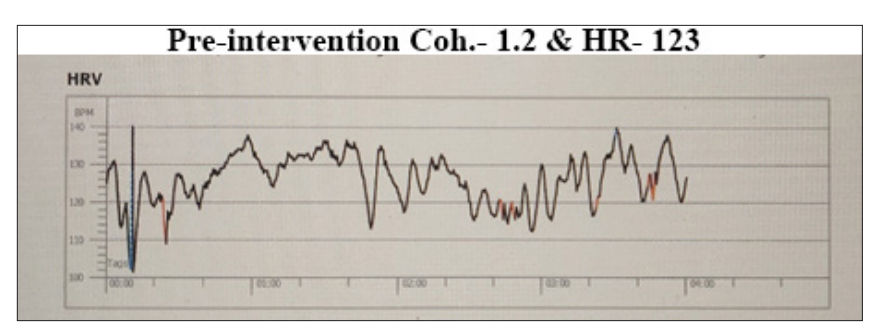

Low coherence indicates that the body is under stress and as you can see from the image, her heart rhythm pattern was erratic.

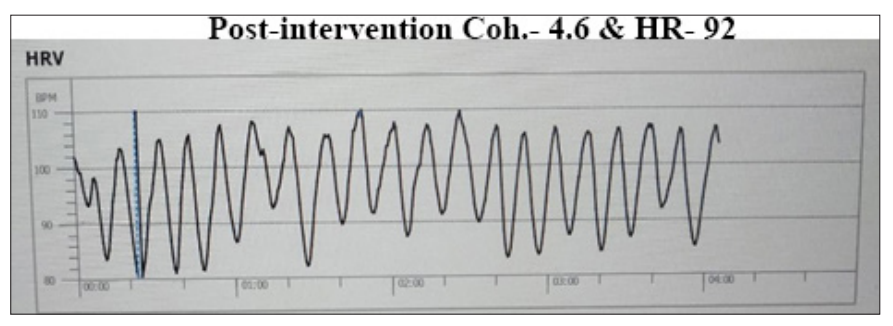

She showed noticeable improvement after 6 sessions of quick coherence training. Her stress score came in the moderate range and anxiety and depression were in mild range. There was a marked improvement in her heart rhythm pattern. Her coherence was 4.6 and heart rate was 92 . Her score on anger and sadness was 5, happiness was 6 and calmness was 7 post intervention.

Results are consistent with past studies such as Jerath R. et al (2015) and S. D. Edward (2016). (21,39)

\section{Conclusion}

The current study is in line with the past research done by S.D. Edwards (2016) on 'Influence of Heartmath Quick Coherence Technique on Psychophysiological Coherence and Feeling States'. The researcher comes to a conclusion that post quick coherence training sessions there was a significant improvement in stress, anxiety, psychophysiological coherence, heart rate and feeling state.

The findings of the present study indicate that the quick coherence technique actually brings about phenomenal results. After the above study the researchers strongly believe that quick coherence technique is of paramount importance as a pivotal tool in managing stress and anxiety. A direct or a cognitive process driven control of emotional state are both indeed valuable and have equally strong effect on the symptoms. The yoga technique of controlled breathing can bring quick relief in stress, anxiety and feeling state. Thus, we can conclude that regular focused breathing can help a person remain mentally and physically healthier. The more a person remains in a positive feeling state the more mentally resilient he or she will become. The heart focused quick coherence technique can be one of the self-help tools to shed all negativity and invite a positive feeling state which is longer lasting. This will allow the person to get rid of anxiety, stress and negative emotions. 
Limitation \& Recommendation

Had the sample size been large enough, the effectiveness of quick coherence technique would have been more apparent. Similar study comparing it with music and other therapies on a larger sample and for a longer duration will definitely give a different perspective to show how different therapies can be instrumental in bringing about a positive change.

\section{References}

1. American Psychological Association. Anxiety. Retrieved from http://www.apa.org/topics/anxiety/index.aspx

2. American Psychological Association. Depression. Retrieved from http://www.apa.org/topics/depression/ index.aspx

3. American Psychiatric Association. Diagnostic and Statistical Manual of Mental Disorders (Fifth Edition). Washington, D.C.: American Psychiatric Association; 2013. 160-161, 222-223.

4. American Psychological Association. Emotion. Retrieved from https://dictionary.apa.org/emotion

5. Appelhans B., Luecken L. (2006) Heart rate variability as an index of regulated emotional responding. Rev. Gen. Psychol. Doi.org/ 10.1037/1089-2680.10.3.229. Retrieved from https://journals.sagepub.com/doi/10.1037/10892680.10.3.229

6. Baum, A. (1990) "Stress, Intrusive Imagery, and Chronic Distress," Health Psychology, 6: 653-675. Retrieved from https://www.apa.org/helpcenter/understanding-chronicstress.

7. Baum, A. \& Polsusnzy, D. (1999) "Health Psychology: Mapping Bio-behavioral Contributions to Health and Illness." Annual Review of Psychology, 50: 137163. Retrieved from https://www.apa.org/helpcenter/ understanding-chronic-stress

8. Bradley R.T., McCraty R., Atkinson M. et al. (2010) Emotion Self-Regulation, Psychophysiological Coherence, and Test Anxiety: Results from an Experiment Using Electrophysiological Measures. Appl Psychophysiol Biofeedback 35: 261-283 (2010). https://doi.org/10.1007/ s10484-010-9134-x. Retrieved from https://link.springer. com/article/10.1007/s10484-010-9134-x

9. Calm with Yoga (2020) Get More Mental Clarity, Emotional Stability, \& Well-being by Activating Heart Coherence. Retrieved from https:/www.calmwithyoga. com/get-more-mental-clarity-emotional-stability-wellbeing-by-activating-heart-coherence/

10. Calm with Yoga (2020) A Step-By-Step Guide to Diaphragmatic Breathing (Belly Breathing). Rerieved from https://www.calmwithyoga.com/diaphragmaticbelly-breathing/

11. Chambers AS, Allen JJB (2002) Vagal tone as an indicator of treatment response in major depression. Psychophysiology3 9:861-864.PMID:12462513 DOI: $10.1111 / 1469-8986.3960861$.Retrieved from https:/www.ncbi.nlm.nih.gov/pmc/articles/ PMC5222529/\#: :text=Heart\%20rate\%20variability\%20 biofeedback\%20(HRV, substance \% 20 use $\% 20$ disorders $\% 20$ (SUDs)
12. emWave system: (EMWave Pro. Coherence training software. HeartMath LLC., CA, USA)

13. Fatisson J, Oswald V, Lalonde F (2016) Influence diagram of physiological and environmental factors affecting heart rate variability: An extended literature overview. Heart Int 11: e32-e40. Retrieved from https://www. journalofdiabetology.org/article.asp?issn=2078-7685; yea $\mathrm{r}=2019$; volume $=10$; issue $=2$; ppage $=48$; epage $=56$; aulast $=$ Trivedi

14. Fiona Jones, Jim Bright, Angela Clow (2018) Stress: myth, theory, and research Archived 2018-05-08 at the Wayback Machine, Pearson Education, 2001, p.4 https://wikivisually.com/wiki/Psychological_stress\#cite note-3

15. Garrett H. E (1966) Statistics in Psychology and Education. International Book Bureau, Hyderabad, India. 184-239.

16. Ginsberg J. P., Berry M. E., Powell D. A. (2010) Cardiac coherence and PTSD in combat veterans. Altern. Ther. Health Med. 16: 52-60. Retrieved from https://pubmed. ncbi.nlm.nih.gov/20653296/

17. Hartmann R, Schmidt FM, Sander C and Hegerl U (2019) Heart Rate Variability as Indicator of Clinical State in Depression. Front. Psychiatry 9: 735. doi: 10.3389/ fpsyt.2018.00735 Retrieved from https://www.frontiersin. org/articles/10.3389/fpsyt.2018.00735/full

18. HeartMath (2014) Coherence. Retrieved from https://www.heartmath.org/articlesof - t h e - h e a r t / t h e - m a t h-of - he a r t m a t h / coherence/\#: : text=\%E2\%80\%9CCoherence $\% 20$ is $\% 20$ the $\% 20$ state $\% 20$ when,manifest $\% 20$ intentions $\% 20$ and $\% 20$ harmonious $\% 20$ outcomes. $\%$ E2\%80\%9D

19. HeartMath Institute(2020)TheQuick Coherence Technique for Adults. Retrieved from https://www.heartmath.org/ resources/heartmath-tools/quick-coherence-techniquefor-adults/Jorina Elbers \& Rollin McCraty (2020) HeartMath approach to self-regulation and psychosocial well-being, Journal of Psychology in Africa, 30 1: 69-79, DOI: $10.1080 / 14330237.2020 .1712797$. Retrieved from https://www.tandfonline.com/doi/s/10.1080/14330237.20 20.1712797? journalCode $=$ rpia20

20. HeartMath. The science of HeartMath. Retrieved from https://www.heartmath.com/science/ and https://www. heartmath.org/research/science-of-the-heart/

21. Jerath R., Crawford M.W., Barnes V.A. et al (2015) SelfRegulation of Breathing as a Primary Treatment for Anxiety. Appl Psychophysiol Biofeedback 40: 107-115. https://doi. org/10.1007/s10484-015-9279-8. Retrieved from https:// link.springer.com/article/10.1007\%2Fs10484-015-9279-8

22. Jorina Elbers \& Rollin McCraty (2020) HeartMath approach to self-regulation and psychosocial well-being, Journal of Psychology in Africa, 30 (1): 69-79, DOI: 10.1080/14330237.2020.1712797. Retrieved form https:// www.tandfonline.com/doi/s/10.1080/14330237.2020.171 2797? journalCode $=$ rpia20

23. Kendra Cherry (2020) Overview of the 6 Major Theories of Emotion. Verywellmind. Retrieved from https://www.verywellmind.com/theories-ofemotion-2795717\#: :text=In\%20psychology $\% 2 \mathrm{C} \% 20$ 
emotion $\% 20$ is $\% 20$ often,personality $\% 2 \mathrm{C} \% 20$ $\operatorname{mood} \% 2 \mathrm{C} \% 20$ and $\% 20$ motivation.

24. Karavidas MK, Lehrer PM, Vaschillo E, Vaschillo B, Marin H, Buyske S, et al. Hassett A. (2007) Preliminary results of an open label study of heart rate variability biofeedback for the treatment of major depression. Applied Psychophysiology and Biofeedback. 32: 19-30. PMID: 17333315 DOI: 10.1007/s10484-0069029-z. Retrieved from https:/www.ncbi.nlm.nih.gov/ pmc/articles/PMC5222529/\#: :text=Heart\%20rate\%20 variability $\% 20$ biofeedback $\% 20$ (HRV,substance $\% 20$ use $\% 20$ disorders $\% 20$ (SUDs)

25. Lovibond, S.H. \& Lovibond, P.F. (1995) Manual for the Depression Anxiety \& Stress Scales. (2 Ed.)Sydney: Psychology Foundation. Retrieved from http://www2.psy. unsw.edu.au/dass/

26. Lucia Giombini (2018) The Coherence of the heart: Heart rate variability. Retrieved from http://www. londonpsychologistonline.com/the-coherence-of-theheart-heart-rate-variability/

27. Lucy H. Field, L., Stephen D. Edwards, David J. Edwards \& Sarah E. Dean (2018) Influence of HeartMath Training Programme on Physiological and Psychological Variables. Global Journal of Health Science; 10(2) 2018, ISSN 19169736 E-ISSN 1916-9744, Published by Canadian Center of Science and Education. URL: https://doi.org/10.5539/ gjhs.v10n2p126. Retrieved from https:/www.heartmath. org/assets/uploads/2018/05/influence-of-heartmathtraining-programme-on-physiological-and-psychologicalvariables.pdf

28. McCraty, R., Atkinson, M., Tiller, W.A., Rein, G. \& Watkins, A.D. (1995) The effects of emotions on short-term power spectrum analysis of heart rate variability. American Journal of Cardiology, 76(14): 1089-1093. Retrieved from https://www.heartmath.org/assets/uploads/2018/03/ influence-of-heartmath-quick-coherence-technique.pdf

29. McCraty, R., Barrios-Choplin, B., Rozman, D., Atkinson, M. \& Watkins, A.D. (1998) The impact of a new emotional self-management program on stress, emotions, heart rate variability, DHEA and cortisol. Integrative Psychological and Behavioral Science, 33(2): 151-170. Retrieved from https://www.heartmath.org/assets/uploads/2018/03/ influence-of-heartmath-quick-coherence-technique.pdf

30. McCraty R., Atkinson M., Tomasino D., Bradley R. T. (2009) The coherent heart: heart-brain interactions, psychophysiological coherence, and the emergence of system-wide order. Integral. Rev. 5: 10-115 Retrieved from https://www.researchgate.net/publication/41393262 The_Coherent_Heart_Heart-Brain_Interactions Psychophysiological_Coherence_and_the_Emergence of_System-Wide_Order

31. McCraty, R. \& Rees, R.A. (2009) The central role of the heart in generating and sustaining positive emotions. In S. Lopez \& C. R Snyder (Eds.), Oxford Handbook of Positive Psychology, (pp. 527-536). New York, NY: Oxford University Press. Retrieved from https://www. heartmath.org/assets/uploads/2018/03/influence-ofheartmath-quick-coherence-technique.pdf
32. McCraty, R. \& Zayas, M.A. (2014) Cardiac coherence, self-regulation, autonomic stability and psychosocial well-being. Frontiers in Psychology, DOI: 10.3389/ fpsyg.2014.01090. Retrieved from https://www. heartmath.org/assets/uploads/2018/03/influence-ofheartmath-quick-coherence-technique.pdf

33. McCraty, R. \& Shaffer, F. (2015) Heart rate variability: New perspectives on physiological mechanisms, assessment of self-regulatory capacity, and health risk. Global Advances in Health and Medicine, 4(1): 46-61. Retrieved from https://www.heartmath.org/assets/uploads/2018/03/ influence-of-heartmath-quick-coherence-technique.pdf

34. Oxford Dictionaries (2018) Anxiety. Oxford University Press. Retrieved from https://en.oxforddictionaries.com/ definition/anxiety

35. Oxford Dictionaries (2018) Depression. Oxford University Press. Retrieved from https://en.oxforddictionaries.com/ definition/depression

36. Oxford Dictionaries (2018) Stress. Oxford University Press. Retrieved from https://en.oxforddictionaries.com/ definition/stress

37. Patel Sheila (2020) Breathing for Life: The Mind-Body Healing Benefits of Pranayama. Retrieved from https:// www.chopra.com/articles/breathing-for-life-the-mindbody-healing-benefits-of-pranayama

38. Psychology and Counseling News (2019) The Science Of Emotion: Exploring The Basics of Emotional Psychology. UWA Online. Retrieved from https://online.uwa.edu/ news/emotional-psychology/\#: :text=According $\% 20$ to $\% 20$ the $\% 20$ American $\% 20$ Psychological,situations $\% 20$ they $\% 20$ find $\% 20$ personally $\% 20$ significant.

39. S.D. Edwards (2016) Influence of Heartmath Quick Coherence Technique on Psychophysiological Coherence and Feeling States. African Journal for Physical Activity and Health Sciences (AJPHES) Volume 22(4:1): 10061018. Retrieved from https://www.heartmath.org/ research/research-library/basic/influence-heartmathquick-coherence-technique-psychophysiologicalcoherence-feeling-states/ \& https://www.heartmath.org/ assets/uploads/2018/03/influence-of-heartmath-quickcoherence-technique.pdf

40. Siepmann M, Aykac V, Unterdorfer J, Petrowski K, Mueck-Weymann M. (2008) A pilot study on the effects of heart rate variability biofeedback in patients with depression and in healthy subjects. Applied Psychophysiology and Biofeedback. 33: 195-201. PMID: 18807175 DOI: 10.1007/s10484-008-9064-z. Retrieved from https://www.ncbi.nlm.nih.gov/pmc/ articles/PMC5222529/\#: : text=Heart\%20rate $\% 20$ variability $\% 20$ biofeedback $\% 20$ (HRV,substance $\% 20$ use $\% 20$ disorders $\% 20$ (SUDs)

41. Social Science Statistics. T-Test Calculator for 2 Independent Means. Retrieved From https://www. socscistatistics.com/tests/studentttest/default2.aspx

42. "Stress". Mental Health America. 2013-11-18. Retrieved 2018-10-01. Retrieved from https://wikivisually.com/ wiki/Psychological_stress\#cite_note-1

43. The times of India (2020). 50\% youth population subjected 
to depression, anxiety due to COVID lockdown finds ILO survey. Retrieved from https://timesofindia.indiatimes. $\mathrm{com} /$ life-style/health-fitness/de-stress/50-youthpopulation-subjected-to-depression-anxiety-due-tocovid-lockdown-finds-ilo-survey/articleshow/77526806. cms

44. Trivedi Gunjan Y, Hemalatha R, Ramani K V (2018) Chronic Diseases and Mind Body Management, an Introduction (Technical Note), Reference No: CMHS0044TEC. Indian Institute of Management; May, 2018. Retrieved from https://www.ijoy.org.in/article. asp? issn $=0973-6131$; year $=2020$; volume $=13$; issue $=3$; spag $\mathrm{e}=255$; epage $=260$; aulast $=$ Trivedi $\#$ ref 2

45. Trivedi Gunjan Y \& Saboo Banshi (2019) Mind-body benefits of chanting and implications of breathing in simple Bhramari practice. Retrieved from https:// wellness-space.net/conference-presentation-mind-bodybenefits-of-chanting-and-implications-of-breathing-insimple-bhramari-practice/

46. Wellness Space (2018) Effect of Zikr on Heart Rate Variability. Retrieved from https://wellness-space.net/ effect-of-zikr-on-heart-rate-variability/

47. Won E, Yong-Ku K (2016) Stress, the autonomic nervous system, and the immune-kynurenine pathway in the etiology of depression. Curr Neuropharmacol 14: 665-73. Retrieved from https://www.ijoy.org.in/article. asp? issn $=0973-6131 ;$ year $=2020 ;$ volume $=13$; issue $=3$; spag $\mathrm{e}=255$; epage $=260$; aulast $=$ Trivedi $\#$ ref 2

Copyright: (C2021 Shilpa Jasubhai. This is an open-access article distributed under the terms of the Creative Commons Attribution License, which permits unrestricted use, distribution, and reproduction in anymedium, provided the original author and source are credited. 